\title{
Exploring hair cortisone concentration as a novel tool to assess chronic stress in sheep with tick-borne fever
}

\author{
Solveig Marie Stubsjøen ${ }^{\mathrm{a}, *}$, Kristin Sørheim ${ }^{\mathrm{b}}$, Matteo Chincarini ${ }^{\mathrm{c}}$, Jon Bohlin ${ }^{\mathrm{d}}$, Emma Brunberg ${ }^{\mathrm{b}}$, \\ Boris Fuchs ${ }^{\mathrm{e}}$, Rupert Palme ${ }^{\mathrm{f}}$, Lise Grøva ${ }^{\mathrm{g}}$ \\ ${ }^{a}$ Norwegian Veterinary Institute, Department of Animal Health and Food Safety, P.O. Box 750 Sentrum, N-0106 Oslo, Norway \\ ${ }^{\mathrm{b}}$ Norwegian Centre for Organic Agriculture (NORSøK), Gunnars veg 6, N-6630 Tingvoll, Norway

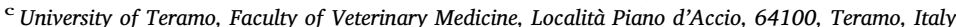 \\ ${ }^{\mathrm{d}}$ Norwegian Institute of Public Health, Division of Epidemiology, Marcus Thranes gate 6, P.O. Box 4404, N-0403 Oslo, Norway \\ e Inland Norway University of Applied Sciences, Faculty of Applied Ecology and Agricultural Sciences, Evenstad, N-2480, Koppang, Norway \\ ${ }^{\mathrm{f}}$ University of Veterinary Medicine, Department of Biomedical Sciences/Unit of Physiology, Pathophysiology and Experimental Endocrinology, Veterinärplatz 1, 1210, \\ Vienna, Austria \\ ${ }^{\mathrm{g}}$ Norwegian Institute of Bioeconomy Research (NIBIO), Gunnars veg 6, N-6630, Tingvoll, Norway
}

\section{A R T I C L E I N F O}

\section{Keywords:}

Animal welfare

Chronic stress

Hair glucocorticoids

Sheep

Tick-borne fever

\begin{abstract}
A B S T R A C T
Tick-borne fever (TBF), caused by the bacterium Anaplasma phagocytophilum and transmitted by the tick Ixodes ricinus, has considerable consequences for animal welfare and economy in the sheep industry. Non-invasive, objective methods to quantify chronic stress are needed in order to evaluate the welfare impact of disease. The aim of this study was 1 ) to evaluate hair cortisol (HC) and hair cortisone ( $\mathrm{HCn}$ ) as biomarkers of chronic stress in sheep with TBF and 2) to test whether there was an association between the development of TBF and concentrations of HC, HCn and faecal cortisol metabolites (FCM) and body weight. The experiment took place in an area with a high prevalence of TBF, and thirty lambs were used in the study. Wool samples were collected in Week 0 , in Week 3 (before turn out on homeland spring pasture), in Week 6 (before turn out on summer rangeland pasture) and at the end of the summer (Week 15). Faecal samples were collected every week (ie. Week 0-6 and Week 15). Symptoms of TBF developed in 15 lambs, of which all recovered from the disease after treatment with antibiotics. HC levels decreased progressively, and significantly, between Week 0, 3, 6 and 15 ( $\mathrm{p}<0.001$ ), while HCn only decreased from Week 0 to Week 3 (p $<0.001$ ) and then remained stable between Week 3-15. FCM increased between Week 0 and $5(\mathrm{p}=0.027)$, and a significant association was found between increased FCM levels in Week 5 and lambs developing clinical signs of TBF $(p=0.022)$. We also found an association between lambs developing clinical signs of TBF and elevated HCn levels in Week $6(p=0.013)$. A slightly lower weight gain at later time points (Week 6 and 15) were found in the affected lambs compared to clinically healthy lambs. Our results indicate local production and/or metabolism of glucocorticoids in the hair follicles. This study strengthens our previous finding of a potential merit of hair cortisone as a biomarker of chronic stress in sheep.
\end{abstract}

\section{Introduction}

Animal welfare is a societal concern, and there is a growing effort worldwide to develop scientifically based indicators for animal welfare assessment. Health is an important part of animal welfare, and the evaluation of the extent of poor welfare during clinical disease is vital (Broom and Corke, 2002). Ticks and tick-borne diseases have received increased attention over the last years and are of great concern for the health and welfare of animals and humans alike (Grøva, 2011). Tickborne fever (TBF) is caused by the bacterium Anaplasma phagocytophilum and transmitted by the tick Ixodes ricinus (Stuen, 2003). This disease is considered to be a major challenge in sheep farming during the grazing season along the coast of south-western Norway, and it is estimated that about 300000 lambs are affected by ticks and A. phagocytophilum in Norway every year (Stuen and Bergstrom, 2001). TBF is initially characterised by high fever, inclusion of the A. phagocytophilum bacterium in neutrophils and severe neutropenia (Stuen, 2003). Clinical signs of TBF often develop within 14 days, starting with an abrupt rise in rectal temperature (often above $41^{\circ} \mathrm{C}$ ), a period of fever of one to two weeks and occasionally coughing,

\footnotetext{
* Corresponding author.

E-mail address: solveig-marie.stubsjoen@vetinst.no (S.M. Stubsjøen).
} 
reduced appetite and dullness (Stuen, 2003). TBF is seldom fatal if it is not complicated with other infections, but indirect losses like reduced weight gain and weaning weight in infected lambs compared to noninfected lambs have been reported (Grøva et al., 2011; Stuen et al., 2002). However, the ensuing immunosuppression may result in secondary infections and diseases like tick pyemia (caused by Staphylococcus spp) and septicaemia, pneumonia and sudden death (caused by Mannheimia haemolytica) (Grøva, 2011), resulting in severely reduced welfare among affected individuals.

Glucocorticoids (GC), also known as stress hormones, are fundamental to how animals integrate, cope with and respond to both predictable and unpredictable perturbations in their environment (Dantzer et al., 2014). However, in the case of chronic systemic elevation of stress hormones, symptoms of allostatic overload appear (McEwen, 2004). The quantification of glucocorticoid metabolites in faeces has been used as a non-invasive method to assess stress in a variety of species (Palme, 2012; Keckeis et al., 2012; Touma and Palme, 2005), and this technique has been validated for sheep (Palme and Möstl, 1997; Palme et al., 1999; Möstl et al., 2002). In sheep, increases in plasma cortisol are reflected by concentrations of faecal cortisol metabolites (FCM) with a delay time of about $12 \mathrm{~h}$ (Palme et al., 1996). Levels of FCM might not be sensitive to acute, light stressors (including handling during sampling procedures), but do reflect the overall stress response over longer periods of time (Möstl and Palme, 2002; Palme, 2012).

Hair cortisol as a biomarker of chronic stress in animals has received increasing attention, and studies have been carried out on for instance cattle, goats and sheep (Gonzalez-de-la-Vara et al., 2011; Battini et al., 2015; Stubsjøen et al., 2015; Salaberger et al., 2016). Hair is a biomaterial that may accumulate GC over weeks to months (Gow et al., 2010) and is thought to be insensitive to the impact of acute stress, including stress caused by handling during sampling procedures. However, some evidence suggests that the capture method may influence HC concentrations in brown bears (Ursus arctos) even after the hair has ceased growing (Cattet et al., 2014). The procedure of collecting hair is simple and non-invasive, and the samples can be stored at room temperature and sent through the mail (Gow et al., 2010). The exact mechanism(s) of glucocorticoid integration in hair is, however, unknown. A major route of integration has been hypothesized to be through diffusion from blood during the growth period of the hair shaft (Gow et al., 2010; Russell et al., 2012). However, several recent studies suggest that local cortisol production may participate as well (Keckeis et al., 2012; Stubsjøen et al., 2015; Salaberger et al., 2016). The source of this local cortisol production is believed to be a parallel, but peripheral, stress axis within the hair follicles (Ito et al., 2005, Slominski et al., 2007). The linkages between, and co-ordination of, the central and peripheral axes are not yet fully understood. Hence, the cortisol concentration in hair may be independently influenced at some times by the peripheral stress axis and concurrently influenced by both axes at other times (Cattet et al., 2014; Sharpley et al., 2011).

The enzyme 11ß-hydroxysteroid-dehydrogenase (HSD) rapidly inactivates glucocorticoids converting cortisol to cortisone, and Raul et al. (2004) suggested a conversion of cortisol to cortisone before its incorporation in hair by type 2 HSD. Previous studies have indicated that cortisone may be a useful additional biomarker for stress research in hair (Raul et al., 2004; Perogamvros et al., 2010; Stalder et al., 2013, Vanaelst et al., 2013), and we recently found that hair cortisone may have a merit as an indicator of chronic stress in sheep (Stubsjøen et al., 2015).

The aim of this study was 1) to evaluate hair cortisol (HC) and hair cortisone $(\mathrm{HCn})$ as biomarkers of chronic stress in sheep with tick-borne fever (TBF) and 2) to test whether there was an association between the development of TBF and concentrations of $\mathrm{HC}, \mathrm{HCn}$ and faecal cortisol metabolites (FCM) and body weight.

\section{Material and methods}

This study was conducted as part of a larger study which aimed to establish early indicators of disease in sheep on pasture by continuous measurement of heart rate, temperature and activity using sensor based technology. The protocol and conduct of this study was approved by the National Animal Research Authority in Norway (FOTS ID 8561).

\subsection{Study animals}

The experiment took place in a sheep farm in Tingvoll municipality in Møre og Romsdal county in Mid-Norway in an area $\left(62^{\circ} 59^{\prime}, 8^{\circ} 14^{\prime}\right)$ with a high prevalence of tick-borne fever. Sheep in Norway are typically housed in the winter and turned out on cultivated grassland close to the farm in the spring. The animals are then turned out on unfenced mountain or forest land during summer, and graze on cultivated grassland before slaughter in the autumn. The lambs in our study were randomly selected from a sheep flock belonging to one of the authors (KS). Thirty lambs of the breed Norwegian White were used in this study. The lambs were aged between 12 and 35 days at the start of the study, and the average birth weight was $6.1 \mathrm{~kg}$ (range: $2.5-8.1 \mathrm{~kg}$ ). Bodyweight was also recorded at study start (week 0), before turnout on homeland spring and summer rangeland pastures (week 3 and 6), as well as in the autumn after collecting the lambs from the rangeland pasture (week 15, Fig. 1). The ewes were fed hay and concentrate twice daily and had access to water ad libitum. The lambs and ewes were housed for the first 3 weeks of the study, and were then turned out on homeland spring pasture ( 3 weeks) and subsequently on summer rangeland pastures ( 9 weeks).

\subsection{Implantation of biologgers}

We surgically implanted a commercially available body temperature logger (Centi-T, Star Oddi, Gardabaer, Iceland) in twenty lambs (8 males and 12 females) and a heart rate logger (Milli-HRT, Star Oddi, Gardabaer, Iceland) in ten out of the twenty lambs ( 2 males and 8 females). Ten lambs were not equipped with sensors and acted as control animals ( 3 males and 7 females). All lambs were equipped with GPS GSM collars (Telespor, Tromsø, Norway) during the grazing period. The Milli-HRT sensors were implanted subcutaneously, while the Centi-T sensors were implanted in the abdomen. Surgery was carried out according to accepted standards in veterinary medicine. Local infiltration along the incision line (ventral midline abdominal \pm left thorax) of $2 \mathrm{ml}$ lidocaine hydrochloride + adrenalin (Lidokel-Adrenalin vet. ${ }^{\circ}$ Kela Laboratoria NV, Hoogstraten, Belgium) and meloxicam (Metacam ${ }^{\circ}$ $0.5 \mathrm{mg} / \mathrm{kg} \mathrm{SC}$, Boehringer Ingelheim Vetmedica $\mathrm{GmbH}$ ) were used to provide analgesia before surgery. The incision length (approximately $1.5 \mathrm{~cm}$ ) was appropriate for the size of the sensors (Centi-T $46 \times 15 \mathrm{~mm}$, Milli-HRT: $39.5 \times 13 \mathrm{~mm}$ ). All sensors were sterilized using propylene gas for twelve hours. The Centi-T sensors were placed into the peritoneal cavity and sutured to the body wall under the umbilicus using a non-absorbable suture (Prolene 2-0). The Milli-HRT sensors were placed subcutaneously on the left thorax at the level of the heart. All devices were programmed and tested before implantation.

\subsection{Clinical observations and treatments}

During the first 3 weeks of the grazing period, when the animals were on homeland pasture, detailed clinical observations of the lambs were performed twice a day, in the morning $(8 \mathrm{am})$ and the afternoon (6 pm), by a veterinarian. Rectal temperature was recorded 2-4 times during the homeland grazing period. Antibiotics (Terramycin prolongatum vet Zoetis ; oxytetracycline $20 \mathrm{mg} / \mathrm{kg}$ im) were administered to all lambs that developed clinical signs of TBF (including fever $>40.5^{\circ} \mathrm{C}$ rectal temperature). Clinical signs were recognized as dullness, lying instead of grazing or playing or not following the 


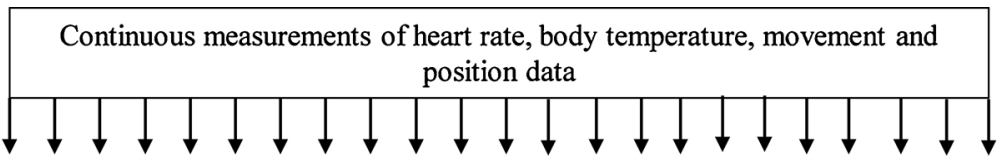

\begin{tabular}{|c|c|c|c|c|c|c|c|}
\hline $\mathrm{Cn} 0)$ & & & Hair (HC1, HCn1) & & & Hair (HC2, HCn2) & Hair \\
\hline$)$ & $\begin{array}{l}\text { aeces } \\
\text { FCM2) }\end{array}$ & $\begin{array}{l}\text { Faeces } \\
\text { (FCM3) }\end{array}$ & $\begin{array}{l}\text { Faeces (FCM4+5) } \\
\text { Body weight (BW2) }\end{array}$ & $\begin{array}{l}\text { Faeces } \\
\text { (FCM6) }\end{array}$ & $\begin{array}{l}\text { Faeces } \\
\text { (FCM7) }\end{array}$ & $\begin{array}{l}\text { Faeces (FCM8) } \\
\text { Body weight (BW3) }\end{array}$ & $\begin{array}{l}\text { Faeces (FCM9) } \\
\text { Body weight (BW4) }\end{array}$ \\
\hline
\end{tabular}

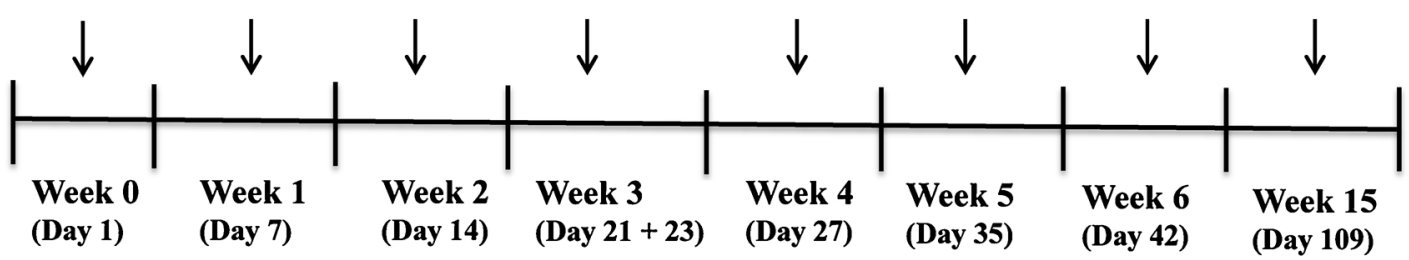

Age 12-35 days.

Faeces sampled before and after surgical implantation of sensors. Lambs turned out on homeland pasture.
Clinical observations. Lambs developing tick-borne fever were treated with antibiotics. (Day 42) (Day 109)

\section{Lambs turned out Lambs returning on rangeland pasture. from rangeland pasture.}

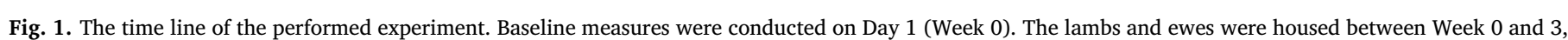

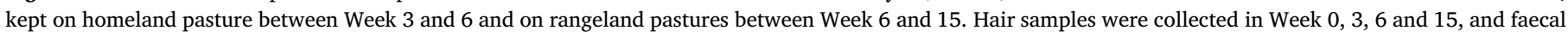
samples were collected every week (ie. Week 0-6 and Week 15). Bodyweight was recorded at birth and in Week 0, 3, 6 and 15 .

mother, increased respiration rate, increased rectal temperature, discoloured conjunctivae, lameness, or more severe clinical signs of acute systemic infections and circulatory collapse. An earlier study on the same farm found an incidence of spring infection in $49 \%$ of lambs, fever in $24 \%$ of lambs and observations of other clinical signs of disease in $23 \%$ of lambs (Grøva et al., 2013). In case of suboptimal wound healing, erythema or infection, wound cleaning and local treatment with antibiotics (Penovet vet. Boehringer Ingelheim Denmark local and/or im) was provided where necessary. Clinical assessments were also performed at the end of the grazing season. The sensors were removed at slaughter and the stored data retrieved.

\subsection{Experimental design}

Fig. 1 shows the time line of the experimental design. On Day 1 (Week 0), wool with a length of $\sim 2-3 \mathrm{~cm}$ was collected from the left shoulder (dorsal aspect of the scapulae) by shaving close to the skin with commercially available clippers. Faecal material was carefully removed from each animal directly from the rectal ampulla, immediately stored on ice and thereafter frozen $\left(-20^{\circ} \mathrm{C}\right)$. Faecal samples were collected every week until the end of the period on homeland pasture (i.e. Week 6) and at the end of the summer when the animals were collected from rangeland pasture (i.e. Week 15). In Week 3 , faecal samples were collected before (3a) and $12 \mathrm{~h}$ after (3b) surgical implantation of sensors. Wool samples were collected every 3 weeks and at the end of the summer (ie. Week 0, 3, 6 and 15), and the regrowth was collected from the same area (left shoulder) at each subsequent measurement time point.

\subsection{Extraction and measurement of steroids from wool}

The wool samples were stored in paper envelopes at room temperature until analysis. The whole length of the wool samples was used for analyses. Extraction and analysis of wool samples was performed as previously described (Stubsjøen et al., 2015; Salaberger et al., 2016). Briefly, aliquots $(0.2-0.4 \mathrm{~g})$ of wool samples were mechanically cleaned and defated with $n$-hexane $(5 \mathrm{ml})$. The dried wool was cut into small fragments $(<5 \mathrm{~mm})$ with scissors. Afterwards a portion of $0.1 \mathrm{~g}$ was extracted with $5 \mathrm{ml}$ methanol $(100 \%)$ for $24 \mathrm{~h}$ with gentle rotation (Thermomixer, stage 5 of $10,37^{\circ} \mathrm{C}$; Eppendorf, Germany). The methanolic phase was dried down, redisolved in $1 \mathrm{ml}$ methanol (80\%) and an aliquot analysed with a cortisol and a cortisone enzyme immunoassay (EIA; details of the assays are given by Palme and Möstl, 1997; Rettenbacher et al., 2004).

\subsection{Extraction and determination of faecal cortisol metabolites (FCM)}

Extraction of all faecal samples $(0.5 \mathrm{~g}$ each) was performed with $80 \%$ methanol, following the standard protocol described by Palme et al. (2013). Faecal cortisol metabolites were determined with an 11oxoaetiocholanolone EIA (details given by Palme and Möstl, 1997) previously validated for sheep (Palme et al., 1999).

\subsection{Statistical analysis}

Statistical analysis was carried out on all data using a different set of methods due to the high variance, lack of normality and the experimental design. In addition to standard linear regression, all results were checked using MM-type robust regression (Wang et al., 2014) and randomization of the outcome (1000 times) with corresponding empirically estimated $p$-values. For the regression models with FCM, HC and $\mathrm{HCn}$ as outcomes, we first adjusted for surgical implantation of sensors (yes/no) and sex, but none of these were significant ( $p>0.1$ ). The FCM, HC and HCn outcomes were additionally all log-transformed. Finally, we adjusted the models for multiple testing based on False Discovery Rate (FDR) methodology (Benjamini and Hochberg, 1995) (2 tests for HC and HCn against TBF and 3 tests for FCM vs TBF). Due to the large variance, only significant results showing approximate normality during randomization and fulfilling $\mathrm{p}<0.05$, after controlling for multiple testing, were considered as significant. Comparisons of the FCM, $\mathrm{HC}$ and $\mathrm{HCn}$ values against time points were performed using first log-transformed linear regression followed by a post hoc Tukeys Honest Significant Difference test (Tukey, 1949). The estimated slopes for bodyweight were performed using standard linear regression adjusting 
for sex and implantation of sensors for respectively TBF and non-TBF cases. All statistical analyses were performed with R (R Core Team, 2017).

\section{Results}

\subsection{Clinical signs of TBF}

Fifteen lambs developed clinical signs (including fever $>40.5^{\circ} \mathrm{C}$ rectal temperature) of TBF. Some animals were reluctant to move or were fully recumbent, but all lambs recovered from the disease after treatment with antibiotics. The first treatments were performed 12 days after the lambs were turned out on the homeland pasture. Two lambs developed clinical signs for the second time on the rangeland pastures after being treated for TBF on the homeland pasture, and two lambs developed clinical signs of TBF after being let out on the rangeland pasture. One lamb died the day following surgery. An autopsy was performed, but the cause of death was inconclusive. Another lamb died on homeland pasture due to coccidiosis. Suboptimal wound healing, erythema or infection occurred in eleven lambs, and wound cleaning and/or (local) treatment with antibiotics was provided where necessary.

\subsection{Faecal cortisol metabolites (FCM)}

The FCM levels had to be log-transformed before the regression analysis due to considerable skewness. Fig. 2 shows log-transformed FCM against Week 0, 1, 2, $3(\mathrm{a}+\mathrm{b}), 4,5,6$ and 15. We performed Tukeys HSD test to explore differences in log FCM between all Weeks. The results from all comparisons have been included as a supplementary file. Concentrations of FCM increased between Week 0-2 $(\mathrm{p}=0.003)$, Week $1-2(\mathrm{p}=0.004)$, Week $0-5(\mathrm{p}=0.027)$ and Week $1-5(\mathrm{p}=0.038)$ and decreased between Week 2 to $3 \mathrm{a}(\mathrm{p}=0.030)$
Table 1

Results from Tukeys HSD test showing significant differences in log FCM between Weeks.

\begin{tabular}{lllll}
\hline $\begin{array}{l}\text { FCM vs } \\
\text { Weeks }\end{array}$ & $\begin{array}{l}\text { Estimated } \\
\text { differences }\end{array}$ & $\begin{array}{l}\text { Lower } \\
95 \% \text { CI }\end{array}$ & $\begin{array}{l}\text { Upper } \\
95 \% \text { CI }\end{array}$ & $\begin{array}{l}\text { P- values (adjusted for } \\
\text { multiple comparisons) }\end{array}$ \\
\hline $0-2$ & 1.104 & 0.244 & 1.965 & 0.003 \\
$1-2$ & 1.085 & 0.217 & 1.953 & 0.004 \\
$0-5$ & 0.847 & 0.052 & 1.642 & 0.027 \\
$1-5$ & 0.828 & 0.025 & 1.631 & 0.038 \\
$2-3 a$ & -0.886 & -1.727 & -0.046 & 0.030 \\
\hline
\end{tabular}

(Table 1). There were no significant differences in FCM between the other Weeks ( $p>0.05$, see supplementary file). Hence, there were no differences in the FCM concentrations between the two measurements performed in Week 3 (ie. before (3a) and after (3b) surgical implantation of sensors). We further tested whether there was an association between FCM concentrations in all Weeks and TBF. We did find a significant association between FCM concentrations measured in Week 5 and lambs developing clinical signs of TBF $\left(R^{2}=0.24, p=0.022\right)$. The regression model was adjusted for the surgical implantation of sensors in a subset (20) of the lambs in Week 3 in addition to sex. However, none of the additional predictors were found to impact the results $(\mathrm{p}>0.1)$.

\subsection{Steroids in hair}

The log-difference of HC levels decreased progressively, and significantly, between Week 0 and Week 3, 6 and 15 (p $<0.001$, Fig. 3). This was not observed for log HCn (Fig. 4), which only decreased substantially from Week 0 to Week $3(\mathrm{p}<0.001)$ and then remained stable between Week 3-15 ( $\mathrm{p}>0.14)$. An association was observed between lambs developing clinical signs of TBF and $\mathrm{HCn} 2(\mathrm{p}=0.013$, Fig. 5) in Week 6, but not for HCn3 (p > 0.1) in Week 15. Again, the

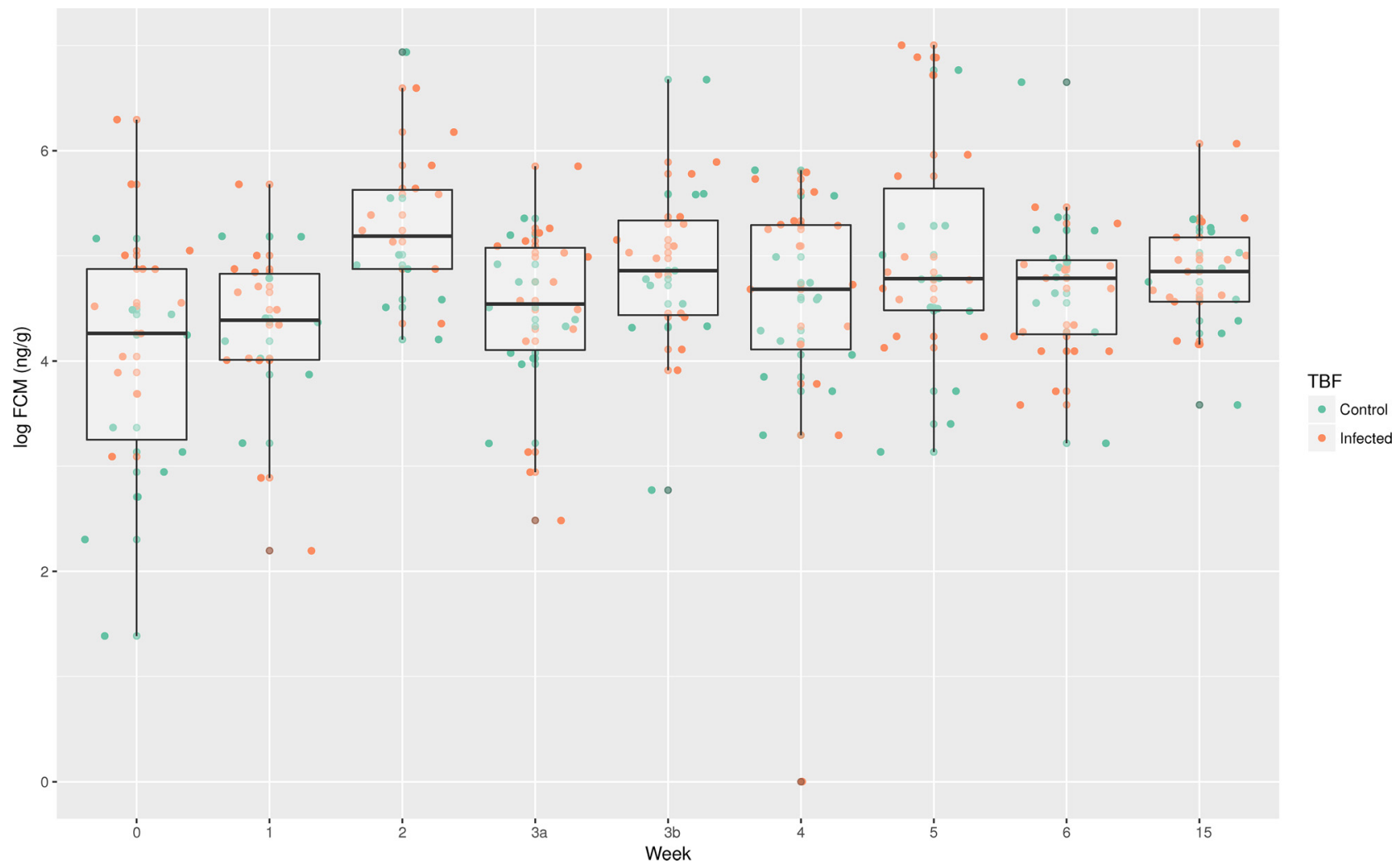

Fig. 2. Log-transformed faecal cortisol metabolite (FCM) levels of 30 lambs in Week 0-6 (including before (3a) and after (3b) surgical implantation of sensors) and Week 15 that developed (infected) or did not develop (control) clinical signs of TBF. 


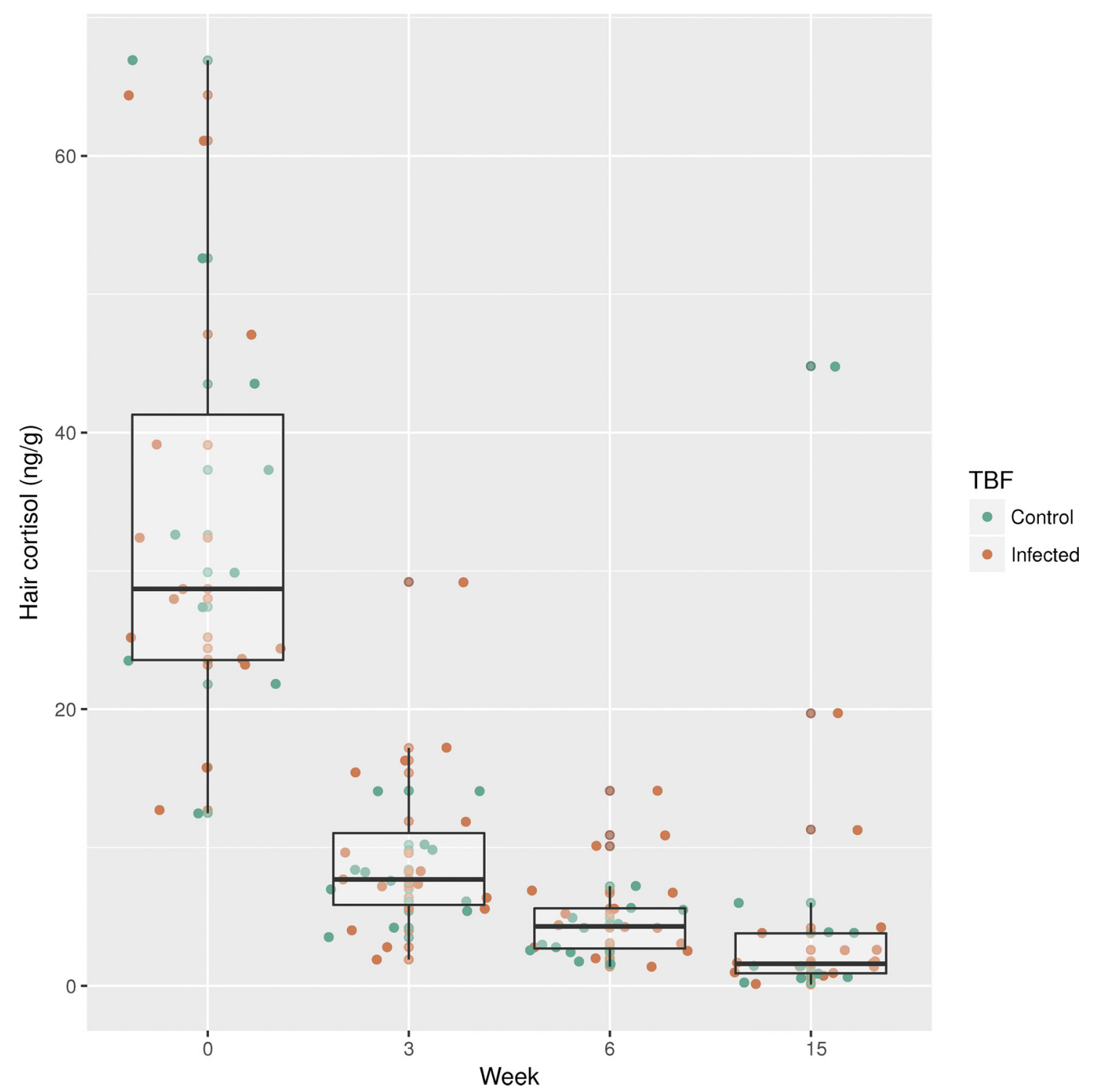

Fig. 3. Hair cortisol levels of 30 lambs in Week 0-6 and 15 that developed (infected) or did not develop (control) clinical signs of TBF.

model was adjusted for the surgical implantation of sensors and sex, of which none were found to be significant $(p>0.1)$. No association was found between TBF and HC2 or HC3 ( $p>0.1$ ).

\subsection{Body weight}

It has previously been noted that there may be a connection between reduced weight gain and TBF. Fig. 6 shows that lambs that developed clinical signs of TBF have a slightly lower weight gain at later time points (Week 6 and 15) than lambs that did not develop clinical signs of TBF (estimated slope 6.93 95\% CI $(6.19,7.67)$ vs 7.96 95\% CI $(7.12,8.80)$. The model was corrected for predictors such as sex and implantation of sensors, but these factors did not contribute significantly to the explanation of the variance in the data $(\mathrm{p}>0.1)$.

\section{Discussion}

\subsection{Prevalence of tick-borne fever (TBF)}

Symptoms of TBF developed in 15 out of 29 lambs (ie. 52\%), of which all recovered from the disease after treatment with antibiotics. Earlier studies found the prevalence of subclinical A. phagocytophilum infection in lambs grazing on tick-infested pastures in Norway to be $80 \%$ (Stuen and Bergstrom, 2001), and a prevalence of 55\% (lambs positive for antibodies to A. phagocytophilum) were found in lambs from 12 different farms in Møre and Romsdal County (Grøva et al., 2011), ie. in the same area as our study was conducted. An earlier study on the same farm looking at incidence of A.phagocytophilum infection, fever and other clinical observations of disease showed an incidence of spring infection in $49 \%$ of lambs, fever in $24 \%$ of lambs and observations of other clinical signs of disease in $23 \%$ of lambs (Grøva et al., 2013). The observations of TBF in our study are thus in accordance with earlier findings.

\subsection{Influence of age}

Both HC and HCn levels decreased from Week 0 to Week 3, and there may have been an influence of age on steroid concentrations in our study. In a previous study, hair cortisol concentrations were found to be significantly higher in 15-day-old heifers $(114.5 \pm 14.43 \mathrm{pg} / \mathrm{mg})$ compared with those from 2-year-old cows (12.15 $\pm 1.85 \mathrm{pg} / \mathrm{mg})$. The authors suggested that this could be due to high serum cortisol concentrations present in late pregnancy that are stimulated by the fetal hypothalamo-pituitary-adrenal (HPA) axis, which indirectly triggers 


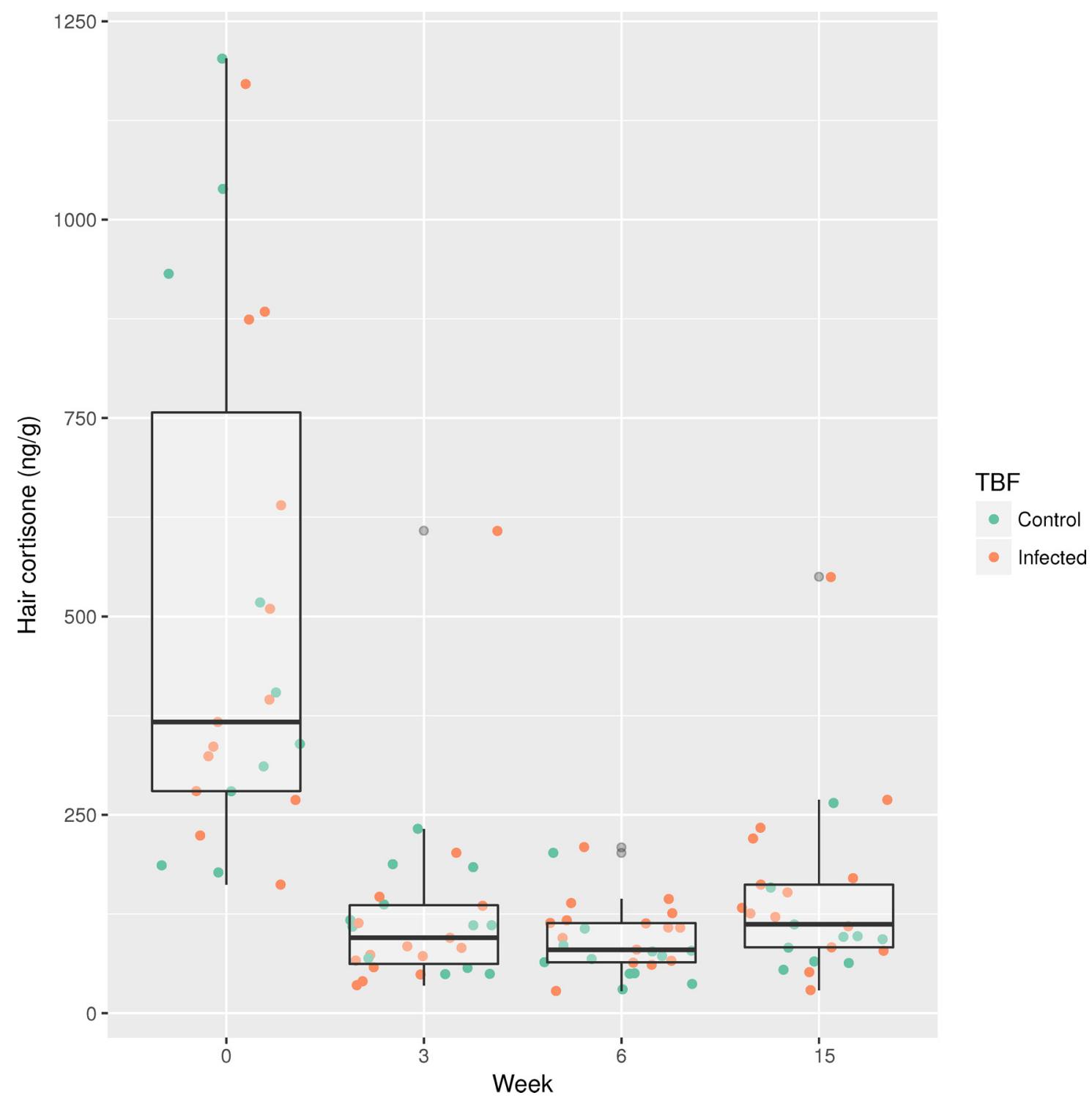

Fig. 4. Hair cortisone levels of 30 lambs in Week 0-6 and 15 that developed (infected) or did not develop (control) clinical signs of TBF.

the cascade for parturition in cows (Gonzalez-de-la-Vara et al., 2011). Similarly, the progressive rise in plasma cortisol concentrations in the fetal sheep during late pregnancy arises from the sequential maturation of the fetal HPA axis. Cortisol from the fetal adrenal gland provides the trigger to the subsequent evolution of maternal endocrine changes that result in increased uterine activity and birth (Challis and Brooks, 1989). Also, ovine amniotic fluid contains cortisol and cortisone (Smith et al., 1977), which may attach to the fetal wool and influence measurements of hair glucocorticoids after birth. This may explain why the HC and HCn concentrations were elevated in Week 0 compared to Week 3.

\subsection{Association between TBF and faecal cortisol metabolites (FCM)}

FCM increased from Week 0 and 1 (when the lambs were housed indoors) to Week 5 (when the lambs had been kept two weeks on homeland pasture). Also, a significant association was found between an increase in FCM levels in Week 5 (FCM7) and lambs developing clinical signs of TBF. In general, FCM is expected to increase during clinical disease, and an increase in FCM has been described in cows with abomasal displacement (Kahrer et al., 2006), in horses with colic (Merl et al., 2000) and in lambs with mild footrot (Stubsjøen et al., 2015). The rise in FCM in Week 5 in response to the developing $A$. phagocytophilum infection was therefore as expected. No association was found between FCM levels measured in Week 6 (FCM8) and TBF, which may be due to that most of the lambs that developed clinical signs of TBF had then been treated with antibiotics. Also, the hypothalamic-pituitary-adrenal (HPA) axis response to chronic stress is far from straight forward (Pawluski et al., 2017). In a review by Dickens and Romero (2013), baseline or stress-induced plasma glucocorticoid levels in laboratory and wild animals were not found to change in a consistent manner in response to chronic stress. Also, Bonier et al. (2009) found inconsistent relationships between plasma GCs and fitness in free-ranging animals. The variability of GC levels under chronic stress may be due to the species studied, the type of stressor or welfare measure, duration of the stress, and techniques used to analyse glucocorticoid levels (Pawluski et al., 2017). The HPA system may also adapt to repeated or long-term exposure to a particular stressor (Dwyer and Bornett, 2004). Hence, the decrease in FCM levels in lambs with TBF between Week 5 and 6 may be due to an effect of treatment or alterations in internal regulation systems due to chronic stress induced by the infection (Stubsjøen et al., 2015). 


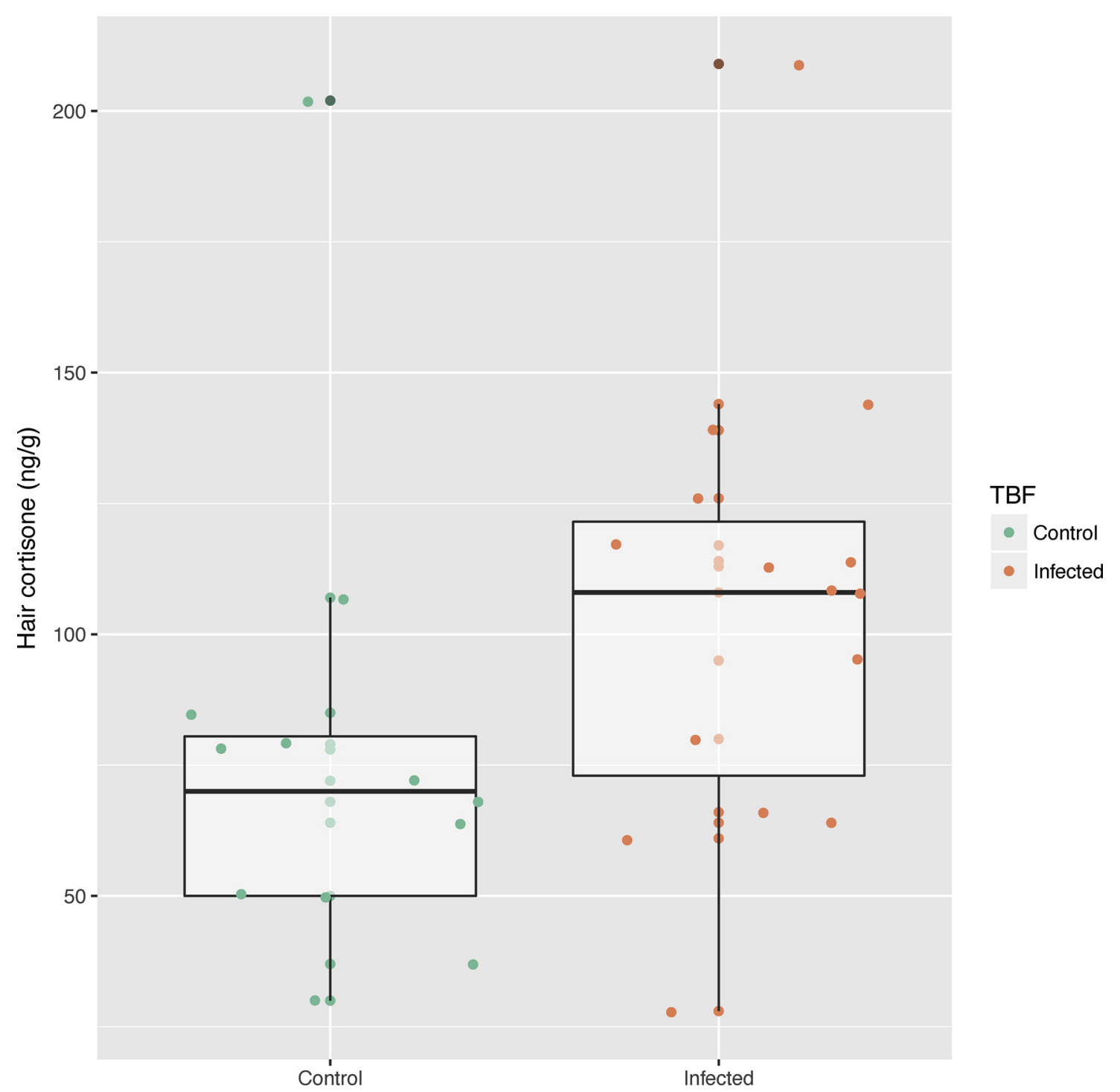

Fig. 5. Hair cortisone levels of 30 lambs in Week 6 that developed (infected) or did not develop (control) clinical signs of TBF.

\subsection{Associations between TBF and steroids in hair}

We found a decrease in hair cortisol levels from Week 3 to Week 6. Concentrations of FCM increased between Week 0 and 5 and in lambs infected with A. phagocytophilum (Week 5). Therefore, HC concentrations would also be expected to increase if the primary mechanism for incorporation was diffusion from blood. However, several previous studies indicate that local cortisol production may participate in the GC integration in hair (Ito et al., 2005; Slominski et al., 2007; Keckeis et al., 2012; Stubsjøen et al., 2015; Salaberger et al., 2016). Keckeis et al. (2012) found that only small amounts of systemically administered radioactive cortisol were deposited (mainly as ${ }^{3} \mathrm{H}$-cortisone) in hair of guinea pigs, while large amounts of unlabeled cortisol were found in the hair. Also, we previously found site-specific and localized responses in the affected hind legs of lambs inoculated with different strains of Dichelobacter nodosus (the main causative agent of ovine footrot), suggesting local production and/or metabolism of glucocorticoids in the hair follicles (Stubsjøen et al., 2015). The FCM concentrations (reflecting adrenocortical activity) increased in response to mild footrot, while the HC concentrations measured in the affected hind legs decreased (Stubsjøen et al., 2015). This does not imply that steroids measured in hair reflect local production only, but that this process is likely influenced by both the central and peripheral HPA-axes. Much of the research reported to date has used samples excluding hair follicles, using the hair shafts only (eg. Raul et al., 2004; Gonzalez-de-la-Vara et al., 2011; Battini et al., 2015; Keckeis et al., 2012; Vanaelst et al., 2013; Stubsjøen et al., 2015; Salaberger et al., 2016). However, based on the formation of hair in a follicle, the use of hair shafts will not exclude cortisol levels measured to originate from local production in the hair follicle (Keckeis et al., 2012). The degree to which the "peripheral" HPA-axis in the hair follicles is affected by, or contributes to, the regulation of the central HPA-axis is still unknown, and the hair cortisol response may therefore be independent of the central HPA-axis response at some times and concurrently influenced by both axes at other times (Cattet et al., 2014; Sharpley et al., 2011). This may also explain the differences seen in this study between the FCM and the hair cortisol responses.

Also, we found an association between lambs developing clinical signs of TBF and elevated hair cortisone levels (HCn2) in Week 6. A local conversion of cortisol to cortisone by the 11ß-hydroxysteroiddehydrogenase (HSD) enzyme could explain why HC levels decreased from Week 3-6 (HC1 to HC2), while HCn overall remained stable and also increased in lambs infected with A. phagocytophilum in Week 6 (HCn2). HSD is a potent dehydrogenase that rapidly inactivates glucocorticoids converting cortisol to cortisone, and Raul et al. (2004) suggested such a conversion of cortisol to cortisone before its 


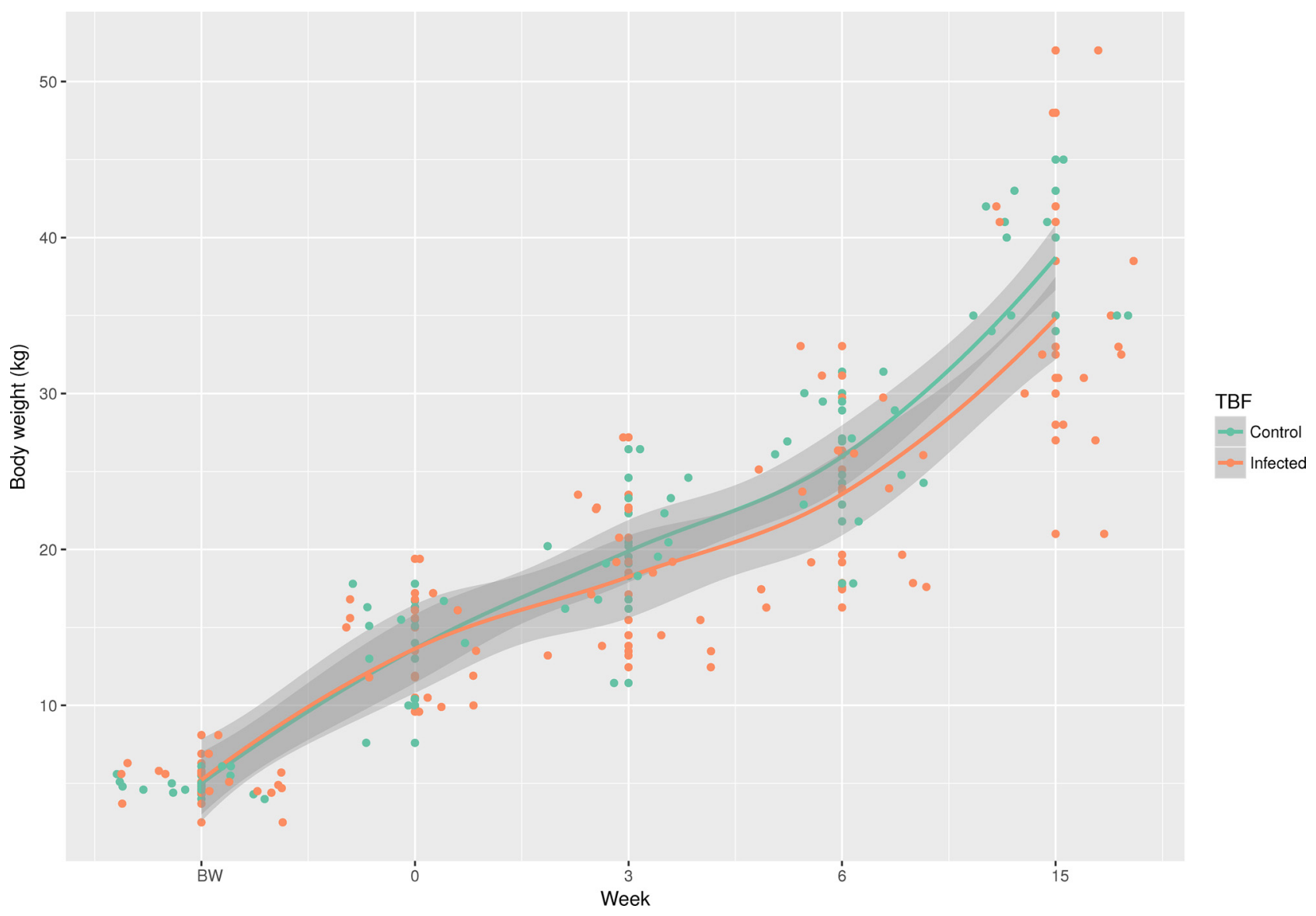

Fig. 6. Body weights of 30 lambs at birth (BW) and in Week 0-6 and 15 that developed (infected) or did not develop (control) clinical signs of TBF.

incorporation in hair by type 2 HSD. In accordance with previous studies (Raul et al., 2004; Stubsjøen et al., 2015), we found that cortisone concentrations were higher than cortisol concentrations in hair. This is in contrast to sheep blood where an opposite ratio was reported (Clements and Newsome, 1973). Different affinities of cortisol and cortisone to the corticosteroid binding protein could explain the difference in concentrations. A better incorporation of cortisone into hair from the bloodstream would also be expected due to cortisone being less polar than cortisol (Raul et al., 2004). Further, Keckeis et al. (2012) found that radiolabeled cortisol administered intraperitoneally in guinea pigs had been metabolized to cortisone prior to its incorporation into the hair shaft. We previously found that $\mathrm{HCn}$ may be a promising indicator of chronic stress in sheep (Stubsjøen et al., 2015), and the present study seems to strengthen this finding.

Wool growth rates have been found to differ among sheep breeds. Priestley and Ryder (1981) found that the overall mean growth rates on shoulder, mid-side and breech in Wensleydale $\mathrm{x}$ Blackface lambs were 0.83, 0.96 and $0.95 \mathrm{~mm} /$ day, respectively, while Schlink et al. (1998) found that fibre length growth rates in Merino wethers differed significantly between groups with low and high staple strength, averaging 393 and $368 \mu \mathrm{m} /$ day $(0.393$ and $0.368 \mathrm{~mm} /$ day $)$, respectively. Similar studies on wool growth rates have, to our knowledge, not been performed in Norwegian sheep breeds. The Norwegian White has crossbred wool, and the mean wool growth rates are probably more similar to the growth rate of the Wensleydale $\mathrm{x}$ Blackface lambs than to the Merino weathers. The rate of wool fibre elongation may also be influenced by nutrition, photoperiod, reproduction, stress, and parasites (Burnard et al., 2017). The wool length was longer in Week 0 and 15 compared to week 3 and 6, which may have resulted in less specific hair steroid measurements in Week 0 and 15 compared to Week 3 and 6. However, we aimed to study chronic stress in lambs with TBF, and the samples obtained in Week 3 (regrown hair from a 3 week indoor housing period) and Week 6 (regrown hair from 3 weeks on homeland pasture exposed to TBF) are therefore the most important measures in our study.

There is a delay between the start of a stressor and the appearance of the signal in the hair, due to the time it takes for the hair to grow from the follicle to the surface of the skin. A few millimetres will be hidden in the skin at the time of sampling the hair shafts, which may have influenced the results. In our study, the steroid levels in the samples obtained in Week 3 (when the animals were still housed) are unlikely to have been affected, while the samples obtained in Week 6 may have been influenced by the background level of steroids when the lambs were housed indoors. This may have masked an increase in steroid levels due to chronic stress caused by TBF. However, it will probably only take a few days for the wool to grow to the surface of the skin, which makes this effect less influential. We also found an association between lambs developing clinical signs of TBF and elevated HCn levels in Week 6, which strengthens the merit of hair cortisone as an indicator of chronic stress in sheep.

\subsection{TBF and body weight}

We observed that lambs that developed clinical signs of TBF had a slightly lower weight gain at later time points (Week 6 and 15) compared to clinically healthy lambs. In accordance with our results, weight reduction as a consequence of an A. phagocytophilum infection has been indicated in several studies (Stuen et al., 1992, Stuen et al., 2002; Grøva et al., 2011). Hence, sheep farmers may experience both indirect loss (i.e. reduced weight gain) and direct loss (deaths) due to lambs being infected with A. phagocytophilum (Grøva, 2011). A number of factors are known to influence the severity of an infection, including the genetic variant of $A$. phagocytophilum, age at infection, immune 
state of the host and the frequency of exposure to infection (Stuen, 2003; Grøva, 2011).

\section{Conclusions}

Tick borne fever caused by $A$. phagocytophilum is seldom fatal unless complicated by secondary infections, but the disease leads to pyrexia, coughing, reduced appetite and dullness. However, associated conditions like tick pyemia, pneumonia and septicaemia cause severe animal welfare problems. In accordance with previous studies, our results indicate local production and/or metabolism of glucocorticoids in the hair follicles. To which degree the systemic stress response of the lambs has affected the local cortisol/cortisone production and/or metabolism in this study is unknown. Therefore, more studies elucidating the incorporation of cortisol and cortisone into hair are needed. Hair cortisone concentrations were found to be increased in lambs that developed clinical signs of TBF, which strengthens our previous finding of a potential merit of hair cortisone as a biomarker of chronic stress in sheep. Further studies are, however, needed in order to validate hair cortisone as an indicator of chronic stress in sheep.

\section{Conflict of interest}

There is no conflict of interest associated with this article.

\section{Acknowledgements}

The Regional Research Foundation (Regionalt Forskningsfond MidtNorge og Innlandet; project number 248077) and the Foundation for Research Levy on Agricultural Products (FFL) and the Agricultural Agreement Research Fund (JA), administered by the Norwegian Agriculture Agency (project number 159136) are acknowledged for funding this study. We thank Edith Klobetz-Rassam for steroid analyses.

\section{Appendix A. Supplementary data}

Supplementary data associated with this article can be found, in the online version, at https://doi.org/10.1016/j.smallrumres.2018.05.009.

\section{References}

Battini, M., Peric, T., Ajuda, I., Vieira, A., Grosso, L., Barbieri, S., Stilwell, G., Prandi, A., Comin, A., Tubaro, F., Mattiello, S., 2015. Hair coat condition: a valid and reliable indicator for on-farm welfare assessment in adult dairy goats. Small Rumin. Res. 123, 197-203.

Benjamini, Y., Hochberg, Y., 1995. Controlling the false discovery rate: a practical and powerful approach to multiple testing. J. R. Stat. Soc. Series B Stat. Methodol. 1, 289-300.

Bonier, F., Martin, P.R., Moore, I.T., Wingfield, J.C., 2009. Do baseline glucocorticoids predict fitness? Trends Ecol. Evol. 24, 634-642.

Broom, D.M., Corke, M.J., 2002. Effects of disease on farm animal welfare. Acta Vet. Brno 71, 133-136.

Burnard, C., Ralph, C., Hynd, P., Edwards, J.H., Tilbrook, A.J., 2017. Hair cortisol and its potential value as a physiological measure of stress response in human and nonhuman animals. Anim. Prod. Sci. 57, 401-414.

Cattet, M., Macbeth, B.J., Janz, D.M., Zedrosser, A., Swenson, J.E., Dumond, M., Stenhouse, G.B., 2014. Quantifying long-term stress in brown bears with the hair cortisol concentration: a biomarker that may be confounded by rapid changes in response to capture and handling. Conserv. Physiol. 2, 1-15.

Challis, J.R.G., Brooks, A.N., 1989. Maturation and activation of hypothalamic-pituitary-adrenal function in fetal sheep. Endocr. Rev. 10, 182-204.

Clements, A.S., Newsome, H.H., 1973. Assay of cortisol, corticosterone, 11-deoxycortisol and cortisone in ovine peripheral and adrenal venous plasma. J. Endocr. 56, 413-419.

Dantzer, B., Fletcher, Q.E., Boonstra, R., Sheriff, M.J., 2014. Measures of physiological stress: a transparent or opaque window into the status, management and conservation of species? Conserv. Physiol. 2. http://dx.doi.org/10.1093/conphys/cou023.

Dickens, M.J., Romero, L.M., 2013. A consensus endocrine profile for chronically stressed wild animals does not exist. Gen. Comp. Endocrinol. 191, 177-189.

Dwyer, C.M., Bornett, H.L., 2004. Chronic stress in sheep: assessment tools and their use in different management conditions. Anim. Welfare 13, 293-304.

Gonzalez-de-la-Vara, M.R., Valdez, R.A., Lemus-Ramirez, V., Vazquez-Chagoyan, J.C., Villa-Godoy, A., Romano, M.C., 2011. Effects of adrenocorticotropic hormone challenge and age on hair cortisol concentrations in dairy cattle. Can. J. Vet. Res. 75, 216-221.

Gow, R., Thomson, S., Rieder, M., Van Uum, S., Koren, G., 2010. An assessment of cortisol analysis in hair and its clinical applications. Forensic Sci. Int. 196, 32-37.

Grøva, L., Olesen, I., Steinshamn, H., Stuen, S., 2011. Prevalence of Anaplasma phagocytophilum infection and effect on lamb growth. Acta Vet. Scand. 53, 30.

Grøva, L., Olesen, I., Steinshamn, H., Stuen, S., 2013. The effect of lamb age to a natural Anaplasma phagocytophilum infection. Small Rumin. Res. 112, 208-215.

Grøva, L., 2011. Tick-Borne Fever in Sheep-Production Loss and Preventive Measures. PhD Thesis. Department of aquaculture and animal science, Norwegian University of Life Sciences, Ås, Norway.

Ito, N., Ito, T., Kromminga, A., Bettermann, A., Takigawa, M., Kees, F., Straub, R.H., Paus, R., 2005. Human hair follicles display a functional equivalent of the hypothalamic-pituitary-adrenal (HPA) axis and synthesize cortisol. FASEB 19, 1332-1334.

Kahrer, E., Möstl, E., Baumgartner, W., 2006. Measurement of cortisol metabolites in faeces of transported cows with abomasal displacement. Bull. Vet. Inst. Pulawy 50, 105-106.

Keckeis, K., Lepschy, M., Schöpper, H., Moser, L., Troxler, J., Palme, R., 2012. Hair cortisol: a parameter of chronic stress? Insights from a radiometabolism study in guinea pigs. J. Comp. Physiol. B 182, 985-996.

Möstl, E., Palme, R., 2002. Hormones as indicators of stress. Dom. Anim. Endocrinol. 23, 67-74.

Möstl, E., Maggs, J.L., Schrötter, G., Besenfelder, U., Palme, R., 2002. Measurement of cortisol metabolites in faeces of ruminants. Vet. Res. Commun. 26, 127-139.

McEwen, B.S., 2004. Protection and damage from acute and chronic stress: allostasis and allostatic overload and relevance to the pathophysiology of psychiatric disorders. Ann. N. Y. Acad. Sci. 1032, 1-7.

Merl, S., Scherzer, S., Palme, R., Möstl, E., 2000. Pain causes increased concentration of glucocorticoid metabolites in horse feces. J. Equine Vet. Sci. 20, 586-590.

Palme, R., Möstl, E., 1997. Measurement of cortisol metabolites in faeces of sheep as a parameter of cortisol concentration in blood. Z. Saugetierkd. - Int. J. Mammal. Biol. 62, 192-197.

Palme, R., Fische, P., Schildorfer, H., Ismail, M.N., 1996. Excretion of infused 14C-steroid hormones via faeces and urine in domestic livestock. Anim. Reprod. 43, 43-63.

Palme, R., Robia Ch Messmann, S., Hofer, J., Möstl, E., 1999. Measurement of faecal cortisol metabolites in ruminants: a non-invasive parameter of adrenocortical function. Wien Tierärztl. Mschr. 86, 237-241.

Palme, R., Touma, C., Arias, N., Dominchin, M.F., Lepschy, M., 2013. Steroid extraction: get the best out of faecal samples. Wien Tierärztl. Mschr. - Vet. Med. Austria 100, $238-246$.

Palme, R., 2012. Monitoring stress hormone metabolites as a useful, non-invasive tool for welfare assessment in farm animals. Anim. Welfare 21, 331-337.

Pawluski, J., Jego, P., Henry, S., Bruchet, A., Palme, R., Coste, C., Hausberger, M., 2017. Low plasma cortisol and fecal cortisol metabolite measures as indicators of compromised welfare in domestic horses (Equus caballus). PLoS One 12, e0182257.

Perogamvros, I., Keevil, B.G., Ray, D.W., Trainer, P.J., 2010. Salivary cortisone is a potential biomarker for serum free cortisol. J. Clin. Endocrinol. Metab. 95, 4951-4958.

Priestley, G.C., Ryder, M.L., 1981. Autoradiographic studies of wool growth rate in Wensleydale crossbred lambs: absence of a marked circadian rhythm. Animal Sci. 33, 259-263.

R Core Team, 2017. R: A Language and Environment for Statistical Computing. R Foundation for Statistical Computing, Vienna, Austria. https://www.R-project.org.

Raul, J.S., Cirimele, V., Ludes, B., Kintz, P., 2004. Detection of physiological concentrations of cortisol and cortisone in human hair. Clin. Biochem. 37, 1105-1111.

Rettenbacher, S., Möstl, E., Hackl, R., Ghareeb, K., Palme, R., 2004. Measurement of corticosterone metabolites in chicken droppings. Brit. Poultry Sci. 45, 704-711.

Russell, E., Koren, G., Rieder, M., Van Uum, S., 2012. Hair cortisol as a biological marker of chronic stress Current status, future directions and unanswered questions. Psychoneuroendocrino 37, 589-601.

Salaberger, T., Millard, M., El Makarem, S., Möstl, E., Grünberger, V., KrametterFrötscher, R., Wittek, T., Palme, R., 2016. Influence of external factors on hair cortisol concentrations. Gen. Comp. Endocrinol. 233, 73-78.

Schlink, C., Mata, G., Lewis, R.M., 1998. Consequences of differing wool growth rates on staple strength of merino wethers with divergent staple strengths. Wool Tech. Sheep Breed. 46, 271-285.

Sharpley, C.F., McFarlane, J.R., Slominski, A., 2011. Stress-linked cortisol concentrations in hair: what we know and what we need to know. Rev. Neurosci. 23, 111-121.

Slominski, A., Wortsman, J., Tuckey, R.C., Paus, R., 2007. Differential expression of HPA axis homolog in the skin. Mol. Cell. Endocrinol. 265-266 (Suppl), 143-149.

Smith, B.T., Worthington, D., Piercy, W.N., 1977. The relationship of cortisol and cortisone to saturated lecithin concentration in ovine amniotic fluid and fetal lung liquid. Endocrinology 101, 104-109.

Stalder, T., Kirschbaum, C., Alexander, N., Bornstein, S.R., Gao, W., Miller, R., Stark, S., Bosch, J.A., Fischer, J.E., 2013. Cortisol in hair and the metabolic syndrome. J. Clin. Endocrinol. Metab. 98, 2573-2580.

Stubsjøen, S.M., Bohlin, J., Dahl, E., Knappe-Poindecker, M., Fjeldaas, T., Lepschy, M., Palme, R., Langbein, J., Ropstad, E., 2015. Assessment of chronic stress in sheep (part I): The use of cortisol and cortisone in hair as non-invasive biological markers. Small Rumin. Res. 132, 25-31.

Stuen, S., Bergstrom, K., 2001. Serological investigation of granulocytic Ehrlichia infection in sheep in Norway. Acta. Vet. Scand. 42, 331-338.

Stuen, S., Hardeng, F., Larsen, H.J., 1992. Resistance to tick-borne fever in young lambs. Res. Vet. Sci. 52, 211-216.

Stuen, S., Bergstrom, K., Palmer, E., 2002. Reduced weight gain due to subclinical Anaplasma phagocytophilum (formerly Ehrlichia phagocytophila) infection. Exp. Appl. Acarol. 28, 209-215. 
Stuen, S., 2003. Anaplasma Phagocytophilum (formerly Ehrlichia Phagocytophila) Infection in Sheep and Wild Ruminants in Norway. A Study on Clinical Manifestation, Distribution and Persistence. PhD Thesis. Department of Sheep and Goat Research, Norwegian School of Veterinary Science, Sandnes, Norway.

Touma, C., Palme, R., 2005. Measuring fecal glucocorticoid metabolites in mammals and birds: the importance of validation. Ann. N. Y. Acad. Sci. 1046, 54-74.

Tukey, J.W., 1949. Comparing individual means in the analysis of variance. Biometrics 5, 99-114.
Vanaelst, B., Michels, N., De Vriendt, T., Huybrechts, I., Vyncke, K., Sioen, I., Bammann, K., Rivet, N., Raul, J.S., Molnar, D., De Henauw, S., 2013. Cortisone in hair of elementary school girls and its relationship with childhood stress. Eur. J. Pediatr. 172, 843-846.

Wang, J., Zamar, R., Marazzi, A., Yohai, V., Salibian-Barrera, M., Maronna, R., Zivot, E., Rocke, D., Martin, D., Maechler, M., Konis, K., 2014. Robust Library. R Package Version 0. pp. 4-16. https://CRAN.R-project.org/package = robust. 